$5-1-2016$

\title{
Symmetric Variants of Logistic Smooth Transition Autoregressive Models: Monte Carlo Evidences
}

\author{
OlaOluwa S. Yaya \\ University of Ibadan, Nigeria, os.yaya@ui.edu.ng \\ Olanrewaju I. Shittu \\ University of Ibadan, Nigeria, oi.shittu@ui.edu.ng
}

Follow this and additional works at: http://digitalcommons.wayne.edu/jmasm

Part of the Applied Statistics Commons, Social and Behavioral Sciences Commons, and the Statistical Theory Commons

\section{Recommended Citation}

Yaya, OlaOluwa S. and Shittu, Olanrewaju I. (2016) "Symmetric Variants of Logistic Smooth Transition Autoregressive Models: Monte Carlo Evidences," Journal of Modern Applied Statistical Methods: Vol. 15 : Iss. 1 , Article 35.

DOI: $10.22237 /$ jmasm/1462077240

Available at: http://digitalcommons.wayne.edu/jmasm/vol15/iss1/35 


\section{Symmetric Variants of Logistic Smooth Transition Autoregressive Models: Monte Carlo Evidences}

\section{Cover Page Footnote}

This work is part of the first author's PhD thesis, conducted under the supervision of the second author. Escribano and Jordá are gratefully acknowledged for providing the OxGAUSS program used. 


\section{Symmetric Variants of Logistic Smooth Transition Autoregressive Models: Monte Carlo Evidences}

\author{
OlaOluwa S. Yaya \\ University of Ibadan \\ Ibadan, Nigeria
}

\author{
Olanrewaju I. Shittu \\ University of Ibadan \\ Ibadan, Nigeria
}

The Smooth Transition Autoregressive (STAR) models are becoming popular in modeling economic and financial time series. The asymmetric type of the model is the Logistic STAR (LSTAR) model, which is limited in its applications as a result of its asymmetric property, which makes it suitable for modelling specific macroeconomic time series. This study was designed to develop the Absolute Error LSTAR (AELSTAR) and Quadratic LSTAR (QLSTAR) models for improving symmetry and performance in terms of model fitness. Modified Teräsvirta's Procedure (TP) and Escribano and Jordá's Procedure (EJP) were used to test for nonlinearity in the series. The performance of the AELSTAR and QLSTAR models showed that TP and EJP realized time series with improved symmetry as indicated by the lower relative frequencies than that realized with the existing LSTAR model. The AELSTAR model performed better than QLSTAR model at higher nonlinearity, and the selection of both models showed evidence of asymptotic property. The AELSTAR and QLSTAR models showed improved symmetry over the existing asymmetric LSTAR model.

Keywords: $\quad$ Nonlinear models, smooth transition autoregressive models, transition function

\section{Introduction}

Smooth Transition Autoregressive (STAR) models have found widespread application in economics and finance. Logistic STAR (LSTAR), a form of the model, is characterized by the asymmetric properties which make it suitable for modelling specific macroeconomic time series. The asymmetric property often limits its application to some symmetric time series. The study was designed to develop the Absolute Error LSTAR (AELSTAR) and Quadratic LSTAR (QLSTAR) models for improving symmetry and performance.

Dr. Yaya is a Lecturer in the Department of Statistics. Email him at: os.yaya@ui.edu.ng. Dr. Shittu is an Associate Professor of Statistics. Email him at: oi.shittu@ui.edu.ng. 


\section{LOGISTIC SMOOTH TRANSITION}

The STAR model was introduced into time series literature by Chan and Tong (1986), who used the cumulative function of the standard normal variable as the transition function in the model. The specification, estimation, and evaluation of the model were considered in Teräsvirta (1994). This model was used to describe non-linearity in the business cycle (Teräsvirta \& Anderson, 1992; Skalin \& Teräsvirta, 1996; 1998) and real exchange rates (Baum, Caglayan, \& Barkoulas, 1998; Liew, Ahmad, \& Sie-Hoe, 2002). Acemoglu and Scott (1994) examined the connection between business cycle, nonlinearity, and asymmetry in the UK labor market and found that the variables are interrelated. Öcal (2000) applied the STAR model on the nonlinearities in growth rates of UK macroeconomic time series: GDP, price, consumption, retail sales, personal disposable income, savings, investment, industrial production, and unemployment, and their findings suggest a three-regime STAR model for modelling GDP, price, and consumption. UK stock market returns have been studied using the Smooth Transition Regression (STR) framework by employing a variety of financial and macroeconomic series that are assumed to influence UK stock returns, namely GDP, interest rates, inflation, money supply, and US stock prices (Aslanidis, Osborn, \& Sensier, 2002). They estimated STR models where the linearity hypothesis is strongly rejected for at least one transition variable. These non-linear models described the in-sample movements of the stock returns series better than the corresponding linear model.

More recent applications are Teräsvirta, van Dijk, and Medeiros (2005), Woodward and Anderson (2009), and Dueker, Sola, and Spagnolo (2006). Teräsvirta et al. (2005) examine the forecast accuracy of linear Autoregressive (AR) and STAR models and concluded that STAR model generally outperforms linear AR models. Dueker et al. (2006) worked on the STAR model and proposed the Contemporaneous Smooth Threshold Autoregressive (C-STAR), model which is a modification of Teräsvirta (1994). This C-STAR model does not require the initial regime to be predetermined and was successfully applied to interest rate modelling. The results indicated that the model is capable of outperforming some competing alternative nonlinear models, especially in terms of relative out of sample forecasting performance. Woodward and Anderson (2009) studied the behavior of the financial markets using the LSTAR model to classify the market in two phases of bull and bear and the movement in the bull and bear were not the same, which confirmed asymmetry in the markets.

The STAR model is of two forms: the Logistic STAR (LSTAR) and Exponential STAR (ESTAR), which have asymmetric and symmetric properties, respectively. Though market data are often asymmetric, the possibility of improving the symmetry of the LSTAR model could lead to models with better 


\section{YAYA \& SHITTU}

parameter estimates and forecasts. Liew et al. (2002) proposed the Absolute Logistic STAR model with transition function that allows a V-shaped symmetry adjustment towards the mean of the series. In their model, mean adjusted data were used, and the performance of their model outperformed that of the LSTAR model. Adebile (2007) proposed the Error Logistic smooth Transition Regression (ELSTR) model with improved asymmetry over the existing LSTAR, and the model performed better in terms of forecasts.

The economic and financial data display different levels of asymmetry; the possibility of improving the asymmetry of LSTAR models may lead to improvement of the model in terms of parameter estimates and forecasts. The performance of the proposed AELSTAR and QLSTAR models in terms of symmetry are then judged based on their similarity in their realization to symmetric ESTAR model.

The remaining part of the work is structured as follows: the STAR model and the proposed models are discussed in following sections; the linearity and model specification testing procedures are then explained; the Monte Carlo simulations are presented; while a final section gives the conclusion.

\section{The General STAR Model}

Following van Dijk, Teräsvirta, and Franses (2002), the general two-regime STAR model of order $p$ observed at $t=1-p, 1-(p-1), \ldots,-1,0,1, N-1, N$ for a univariate time series $y_{t}$ is

$$
y_{t}=\phi_{1}^{\prime} \tilde{\mathbf{y}}_{t}^{(p)}\left(1-\mathrm{F}\left(s_{t} ; \gamma, c\right)\right)+\phi_{2}^{\prime} \tilde{\mathbf{y}}_{t}^{(p)} \mathrm{F}\left(s_{t} ; \gamma, c\right)+\epsilon_{t}
$$

where $\tilde{\mathbf{y}}_{t}^{(p)}=\left(1-y_{t-1}, \ldots, y_{t-p}\right)^{\prime}, \phi_{i}=\left(\phi_{i 0}, \phi_{i 1}, \ldots, \phi_{i p}\right)^{\prime}$, and $i=\{1,2\}$. The $\epsilon_{t}$ are assumed to be a difference sequence with respect to the history of the time series up to time $t-1$, denoted by $\Omega_{t-1}=\left\{y_{t-1}, y_{t-2}, \ldots, y_{1-(p-1)}, y_{t-p}\right\}$. That is $\mathrm{E}\left(\epsilon_{t}^{2} \mid \Omega_{t-1}\right)=\sigma^{2}$ and $\mathrm{E}\left(\epsilon_{t} \mid \Omega_{t-1}\right)=0$ or $\mathrm{E}\left(\epsilon_{t}^{2} \mid \Omega_{t-1}\right)=\sigma_{t}^{2}$ for the heteroscedastic STAR model.

Following Tsay (2005), the transition function $\mathrm{F}\left(y_{t-d} ; \gamma, c\right)$ can be a logistic, exponential, or cumulative continuous distribution function third order continuously differentiable with respect to $\gamma$ (Escribano \& Jordá, 1999; 2001), and is bounded between 0 and 1 for both LSTAR and ESTAR specifications. It defines regime-specific dynamics that govern the transition between 0 and 1 regimes, depending on the values of the transition variable relative to the slope $\gamma$ and of the 


\section{LOGISTIC SMOOTH TRANSITION}

location parameters $c$. The smoothness parameter $\gamma>0$ determines the speed of transition of the transition function towards the inner or outer regime, as well as the degree of nonlinearity. As $\gamma \rightarrow 0$, both LSTAR and ESTAR functions converge to constant, and the models become linear AR models. The delay parameter $d$ of the transition variable can take values in the range of $1 \leq d \leq p$ or $d>p$ (van Dijk, 1999; Siliverstovs, 2005).

The LSTAR function of the first order is

$$
\mathrm{F}\left(y_{t-d} ; \gamma, c\right)=\frac{1}{1+\exp \left[-\gamma\left(y_{t-d} ; c\right)\right]}, \gamma>0,
$$

while the ESTAR function is defined as

$$
\mathrm{F}\left(y_{t-d} ; \gamma, c\right)=1-\exp \left[-\gamma\left(y_{t-d} ;-c\right)^{2}\right], \gamma>0
$$

\section{The Absolute Error and Quadratic LSTAR Models}

The transition variable can assume a lagged endogenous transition variable $y_{t-d}$ as in Teräsvirta (1994), an exogenous variable, $z_{t}$ in Adebile (2007), a linear and nonlinear function of lagged endogenous variables, $\mathrm{h}\left(\tilde{y}_{t} ; \alpha\right)$, which depends on a $(q \times 1)$ parameters vector or a linear time trend $t$ which gives rise to a model with smoothly changing parameters (van Dijk et al., 2002). The absolute value of the random error term, $t$, from the initial $\operatorname{AR}(p)$ and the quadratic function at lag, $d$ (that is $y_{t-d}^{2}+b_{y t-d}$ ), are assumed to cause the transition from one regime to another in this paper. These are the AELSTAR and QLSTAR transition functions which give rise to AELSTAR and QLSTAR models, respectively, once they are substituted in the general STAR model.

The transition functions are

$$
\mathrm{F}\left(y_{t-d} ; \gamma, c\right)=\frac{1}{1+\exp \left[-\gamma\left(\left|\epsilon_{t-d}\right|-c\right)\right]}-\frac{1}{2}, \gamma>0
$$

and 


$$
\mathrm{F}\left(y_{t-d} ; \gamma, c\right)=\frac{1}{1+\exp \left[-\gamma\left(y_{t-d}^{2}+b y_{t-d}-c\right)\right]}-\frac{1}{2}, \gamma>0
$$

for AELSTAR and QLSTAR models, respectively. The parameters in the transition function are as defined earlier in (2) above. The $\left|\epsilon_{t-d}\right|$ is the absolute lagged error, and $b$ is used to stabilize the transition variable $y_{t-d}$ with $b= \pm 1$. The two transition functions above can be compared with the original LSTAR function of Teräsvirta (1994). Teräsvirta (1994) suggests subtracting 1/2 in order to ease the derivation of the test statistics (van Dijk et al., 2002), and this has been dropped in the proposed functions, Monte Carlo's procedures in this work, and the nonlinear parameters estimation.

In the AELSTAR function in (4), as the slope $\gamma$ increases, $\mathrm{F}\left(\epsilon_{t-d} ; \gamma, c\right)$ quickly changes from 0 to 1 . The switching between these regimes also depends on the contribution of the absolute lagged endogenous variable, $\left|\epsilon_{t-d}\right|$. Increasing the slope $\gamma$ further $(\gamma \rightarrow \infty)$ makes the transition function to the Self-Exciting Threshold Autoregressive (SETAR) in the context of STAR modelling, which is another variant of regime switching model. At $\gamma=0, \mathrm{~F}\left(\epsilon_{t-d} ; \gamma, c\right)=0.5$, and hence the $\operatorname{LSTAR}(p)$ model becomes the linear Autoregressive $\operatorname{AR}(p)$ model. The QLSTAR function in (5) has similar properties to the LSTAR function by changing smoothly from 0 to 1 as $\gamma$ increases and this also depends on the value of the quadratic expression which forces the LSTAR function to symmetric function. At $y_{t-d}^{2}+b y_{t-d}=c, F\left(c_{t-d} ; \gamma, c\right)=0.5$, hence the model is linear. Since $y_{t-d}^{2}+b y_{t-d} \geq c$, the quadratic inequality then has real roots, which implies the values of the transition variables $y_{t-d}$ to be $y_{t-d}=-b \pm \sqrt{b^{2}+4 c}$ for real roots using general quadratic function. For complex solutions (i.e. $b^{2}<4 c$ ) there is a discontinuation in the transition from $y_{t-d}$ to $y_{t-d-1}$. In the QLSTAR function in (5), the quadratic function in the transition variable as well as the slope parameter causes the transition to switch from one regime to the other, thereby absorbing the shock caused when the slope parameter, $\gamma$, suddenly increases or decreases. Unlike the traditional LSTAR function, the QLSTAR function produces a smooth symmetric realization.

\section{The Shapes of the Proposed Transition Functions}

Here, the original LSTAR and ESTAR functions are shown to be S and U shaped, respectively. Also, the Taylor series approximations (Teräsvirta, 1994; Escribano 


\section{LOGISTIC SMOOTH TRANSITION}

\& Jordá, 2001) to the functions are plotted alongside with the original LSTAR function.

The proposed transition functions, AELSTAR and QLSTAR, are considered here, and empirical analyses are given to investigate the shape and behavior of the functions. The value of the intercept, $c$, is fixed at 0.05 , and that of the slope, $\gamma$, is varied as $\gamma=\{1,10,100\}$ for the original and proposed transition functions. Hypothetical values are then assigned for $\left|\epsilon_{t-d}\right|$ and $y_{t-d}$, and the corresponding values of $\mathrm{F}(\cdot)$ are generated in both cases. The $\mathrm{F}(\cdot)$ is then plotted on $\left|\epsilon_{t-d}\right|$ for the case of the AELSTAR function and on $y_{t-d}$ for the case of the QLSTAR function. The proposed functions are then compared with the original LSTAR function.

Figure 1 is the graph of the LSTAR function plotted on values of $s_{t}=y_{t-d}$ for $\gamma=1,10$, and 100. At $\gamma=1$, a straight line approximation is obtained; at $\gamma=10$, there is a slower transition from $\mathrm{F}\left(s_{t}=y_{t-d}\right)=0$ to $\mathrm{F}\left(s_{t}=y_{t-d}\right)=1$ and therefore the shape of the LSTAR function is S. The transition is faster at $\gamma=100$, and the shape of the LSTAR function at this point is mirrored $\mathrm{Z}$. Both $\mathrm{S}$ and mirrored $\mathrm{Z}$ are asymmetric shapes. This reconfirms the asymmetric property of the LSTAR function. The point $y_{t-d}=c$ is the switch-point between the regime, and the graphs of the logistic function with various smoothness parameters meet at $\mathrm{F}(c ; \gamma, c)=0.5$.

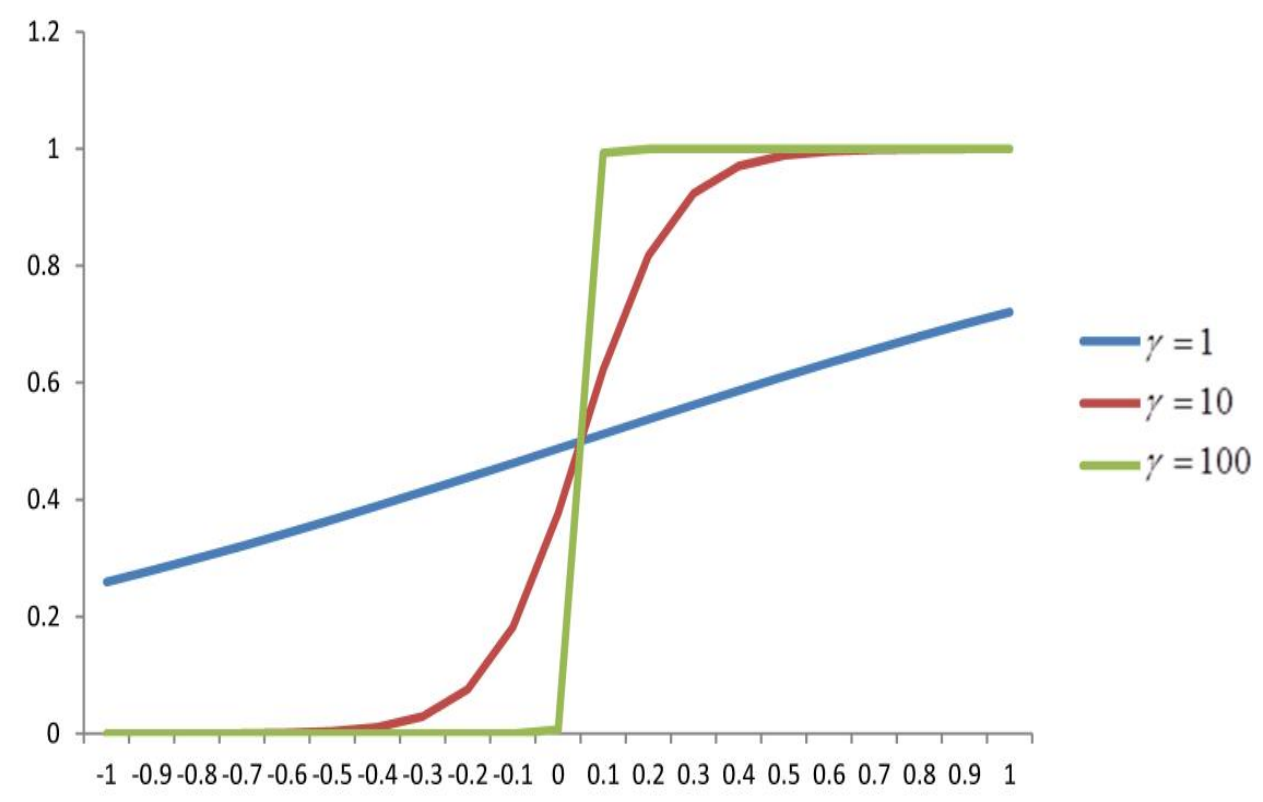

Figure 1. Behavior of the LSTAR function for different values of the slope parameter 


\section{YAYA \& SHITTU}

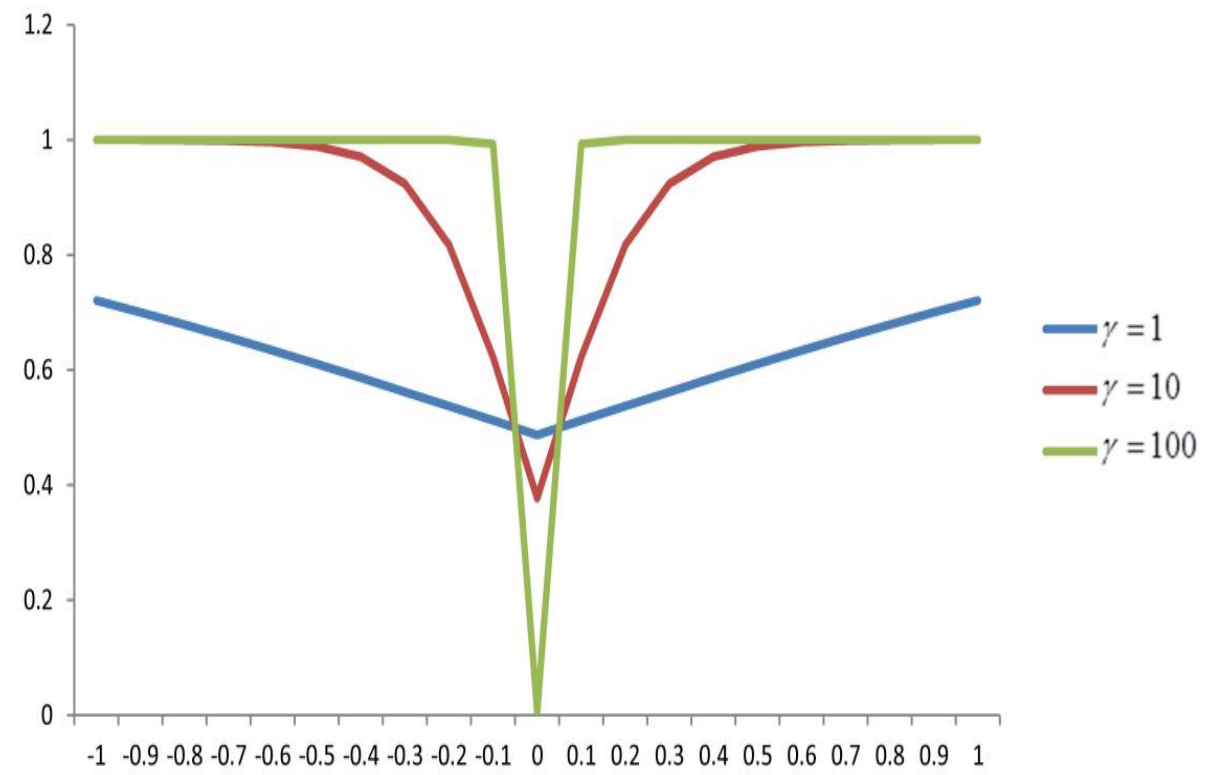

Figure 2. Behavior of the AELSTAR function for different values of the slope parameter

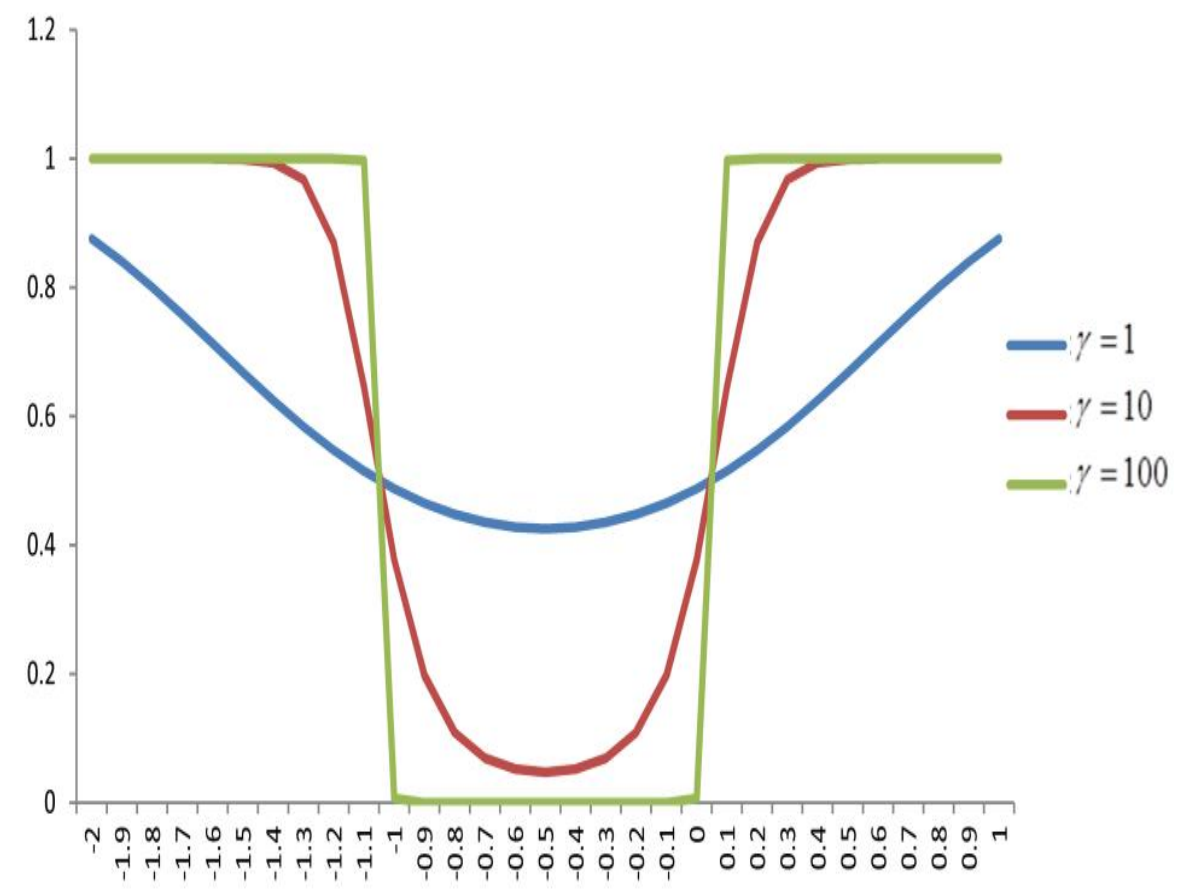

Figure 3. Behavior of the QLSTAR function for different values of the slope parameter 


\section{LOGISTIC SMOOTH TRANSITION}

Figure 2 is the AELSTAR function. At $\gamma=1$, a wider V shape is obtained, and this becomes thinner as $\gamma$ increases. The thinnest V shape obtained is for $\gamma=100$. The $\mathrm{V}$ shapes obtained are reflective of the symmetric nature of the AELSTAR transition. Figure 3 is the QLSTAR function plotted on values of $s_{t}=y_{t-d}$, and shows that the widest $U$ shape is obtained for $\gamma=1$; this shape becomes thinner as $\gamma$ increases. The $\mathrm{U}$ shape obtained is symmetric; hence the QLSTAR function is symmetrical.

\section{Linearity Testing Procedures}

The proposed LSTAR transition functions in (4) and (5) are defined with $1 / 2$ subtracted in order to ease the derivation of the linearity tests.

\section{The AELSTAR Transition Function}

The third order Taylor series approximation of the AELSTAR transition function around the null hypothesis $\gamma=0$ is

$$
\begin{gathered}
\left.\mathrm{F}\left(\epsilon_{t-d} ; \gamma, c\right) \approx \mathrm{F}\left(\epsilon_{t-d} ; \gamma, c\right)\right|_{\gamma=0}+\left.\gamma \frac{\partial \mathrm{F}\left(\epsilon_{t-d} ; \gamma, c\right)}{\partial \gamma \cdot 1 !}\right|_{\gamma=0}+\left.\gamma^{2} \frac{\partial^{2} \mathrm{~F}\left(\epsilon_{t-d} ; \gamma, c\right)}{\partial \gamma^{2} \cdot 1 !}\right|_{\gamma=0} \\
+\left.\gamma^{3} \frac{\partial^{3} \mathrm{~F}\left(\epsilon_{t-d} ; \gamma, c\right)}{\partial \gamma^{3} \cdot 1 !}\right|_{\gamma=0}
\end{gathered}
$$

where
a) $\mathrm{F}\left(\epsilon_{t-d} ; \gamma, c\right)=\left\{1+\exp \left[-\gamma\left(\left|\epsilon_{t-d}\right|-c\right)\right]\right\}^{-1}-\frac{1}{2},\left.\mathrm{~F}\left(\epsilon_{t-d} ; \gamma, c\right)\right|_{\gamma=0}=0$
b) $\frac{\partial \mathrm{F}\left(\epsilon_{t-d} ; \gamma, c\right)}{\partial \gamma}=\left(\left(\left|\epsilon_{t-d}\right|-c\right) \exp \left[-\gamma\left(\left|\epsilon_{t-d}\right|-c\right)\right]\right)\left(\left\{1+\exp \left[-\gamma\left(\left|\epsilon_{t-d}\right|-c\right)\right]\right\}^{2}\right)^{-1}$,

$$
\left.\frac{\partial \mathrm{F}\left(\epsilon_{t-d} ; \gamma, c\right)}{\partial \gamma}\right|_{\gamma=0}=\frac{1}{4}\left(\left|\epsilon_{t-d}\right|-c\right)
$$


c) $\frac{\partial^{2} \mathrm{~F}\left(\epsilon_{t-d} ; \gamma, c\right)}{\partial \gamma^{2}}=2\left(\left|\epsilon_{t-d}\right|-c\right)^{2}\left\{1+\exp \left[-\gamma\left(\left|\epsilon_{t-d}\right|-c\right)\right]\right\}^{-3}\left(\exp \left[-\gamma\left(\left|\epsilon_{t-d}\right|-c\right)\right]\right)^{2}$

$$
-\left(\left|\epsilon_{t-d}\right|-c\right)^{2} \exp \left[-\gamma\left(\left|\epsilon_{t-d}\right|-c\right)\right]\left\{1+\exp \left[-\gamma\left(\left|\epsilon_{t-d}\right|-c\right)\right]\right\}^{-2},
$$

$\left.\frac{\partial^{2} \mathrm{~F}\left(\epsilon_{t-d} ; \gamma, c\right)}{\partial \gamma^{2} \cdot 2 !}\right|_{\gamma=0}=0$

$\frac{\partial^{3} \mathrm{~F}\left(\epsilon_{t-d} ; \gamma, c\right)}{\partial \gamma^{3}}=6\left(\left|\epsilon_{t-d}\right|-c\right)^{3}\left\{1+\exp \left[-\gamma\left(\left|\epsilon_{t-d}\right|-c\right)\right]\right\}^{-4}\left(\exp \left[-\gamma\left(\left|\epsilon_{t-d}\right|-c\right)\right]\right)^{3}$

$$
\begin{aligned}
& -2\left(\left|\epsilon_{t-d}\right|-c\right)^{3} \exp \left[-\gamma\left(\left|\epsilon_{t-d}\right|-c\right)\right]\left\{1+\exp \left[-\gamma\left(\left|\epsilon_{t-d}\right|-c\right)\right]\right\}^{-3} \\
& +\left(\left|\epsilon_{t-d}\right|-c\right)^{3} \exp \left[-\gamma\left(\left|\epsilon_{t-d}\right|-c\right)\right]\left\{1+\exp \left[-\gamma\left(\left|\epsilon_{t-d}\right|-c\right)\right]\right\}^{-2}
\end{aligned}
$$$$
-2\left(\left|\epsilon_{t-d}\right|-c\right)^{3}\left(\exp \left[-\gamma\left(\left|\epsilon_{t-d}\right|-c\right)\right]\right)^{2}\left\{1+\exp \left[-\gamma\left(\left|\epsilon_{t-d}\right|-c\right)\right]\right\}^{-3}
$$

d) $\left.\frac{\partial^{3} \mathrm{~F}\left(\epsilon_{t-d} ; \gamma, c\right)}{\partial \gamma^{3} \cdot 3 !}\right|_{\gamma=0}=\frac{1}{8}\left(\left|\epsilon_{t-d}\right|-c\right)^{3}$

Putting (a)-(d) above in (6),

$$
\begin{aligned}
\mathrm{F}\left(\epsilon_{t-d} ; \gamma, c\right) & =0+\gamma \frac{1}{4} \frac{\left|\epsilon_{t-d}\right|-c}{1 !}+\frac{0}{2 !}+\gamma^{3} \frac{1}{8} \frac{\frac{1}{4}\left(\left|\epsilon_{t-d}\right|-c\right)^{3}}{3 !} \\
& =\frac{1}{4} \frac{\gamma\left(\left|\epsilon_{t-d}\right|-c\right)}{1 !}+\frac{1}{48} \gamma^{3}\left(\left|\epsilon_{t-d}\right|-c\right)^{3} \\
=-\left(\frac{1}{4} c \gamma+\frac{1}{48} \gamma^{3} c^{3}\right) & +\left(\frac{1}{4} \gamma+\frac{\gamma^{3} c^{3}}{16}\right)\left|\epsilon_{t-d}\right|-\left(\frac{1}{16} c \gamma^{3}\left|\epsilon_{t-d}\right|^{2}\right)+\left(\frac{1}{48} \gamma^{3}\left|\epsilon_{t-d}\right|^{3}\right)
\end{aligned}
$$

The two-regime STAR model in (1) is equivalent to the LSTAR model

$$
y_{t}=\phi_{1}^{\prime} \tilde{\mathbf{y}}_{t}^{(p)}+\phi_{2}^{\prime} \tilde{\mathbf{y}}_{t}^{(p)} \mathrm{F}\left(\epsilon_{t-d} ; \gamma, c\right)+\epsilon_{t}
$$

with the transition function replaced by AELSTAR function. Substituting the approximated AELSTAR function in (7) in the AELSTAR model above gives 


\section{LOGISTIC SMOOTH TRANSITION}

$$
y_{t}=\phi_{1}^{\prime} \tilde{\mathbf{y}}_{t}^{(p)}+\phi_{2}^{\prime} \tilde{\mathbf{y}}_{t}^{(p)}\left[\begin{array}{c}
-\left(\frac{1}{4} c \gamma+\frac{1}{48} \gamma^{3} c^{3}\right)+\left(\frac{1}{4} \gamma+\frac{\gamma^{3} c^{3}}{16}\right)\left|\epsilon_{t-d}\right| \\
+\left(\frac{1}{16} c \gamma^{3}\left|\epsilon_{t-d}\right|^{2}\right)+\left(\frac{1}{48} \gamma^{3}\left|\epsilon_{t-d}\right|^{3}\right)
\end{array}\right]+\epsilon_{t}
$$

which is equivalent to the auxiliary regression model

$$
y_{t}=\gamma_{0}^{\prime} \tilde{y}_{t}^{(p)}+\gamma_{1}^{\prime} \tilde{y}_{t}^{(p)}\left|\epsilon_{t-d}\right|+\gamma_{2}^{\prime} \tilde{y}_{t}^{(p)}\left(\left|\epsilon_{t-d}\right|\right)^{2}+\gamma_{3}^{\prime} \tilde{y}_{t}^{(p)}\left(\left|\epsilon_{t-d}\right|\right)^{3}+\vartheta_{t} .
$$

Because $\gamma_{i}(i=0, \ldots, 3)$ do not exist in real sense since they are parameters of the model, compute the corresponding estimates for them based on the regression model

$$
y_{t}=\beta_{0}^{\prime} \tilde{y}_{t}^{(p)}+\beta_{1}^{\prime} \tilde{y}_{t}^{(p)}\left|\epsilon_{t-d}\right|+\beta_{2}^{\prime} \tilde{y}_{t}^{(p)}\left(\left|\epsilon_{t-d}\right|\right)^{2}+\beta_{3}^{\prime} \tilde{y}_{t}^{(p)}\left(\left|\epsilon_{t-d}\right|\right)^{3}+\vartheta_{t},
$$

which is equivalent to

$$
\vartheta_{t}=\beta_{0}^{\prime} \tilde{y}_{t}^{(p)}+\beta_{1}^{\prime} \tilde{y}_{t}^{(p)}\left|\epsilon_{t-d}\right|+\beta_{2}^{\prime} \tilde{y}_{t}^{(p)}\left(\left|\epsilon_{t-d}\right|\right)^{2}+\beta_{3}^{\prime} \tilde{y}_{t}^{(p)}\left(\left|\epsilon_{t-d}\right|\right)^{3}+\varsigma_{t},
$$

where $\beta_{i}^{\prime} \tilde{y}_{t}^{(p)}, i=0,1,2,3$ are functions of $c$ and $\gamma$. The residuals $\vartheta_{t}$ and $\varsigma_{t}$ are from the two auxiliary regressions, and are $\operatorname{NID}\left(0, \sigma^{2}\right)$. So the regression above is performed by regressing $\vartheta_{t}$ on the series of regressors $\tilde{y}_{t}^{(p)}$ and $\tilde{y}_{t}^{(p)}\left(\left|\epsilon_{t-d}\right|\right)^{2},(i=1$, $2,3)$. At this stage, the existence of AELSTAR process depends on the parameters $\beta_{1}^{\prime}, \beta_{2}^{\prime}, \beta_{3}^{\prime}$, which should not all be zeros. This further establishes the nonlinearity of the AELSTAR $(p)$ model. So the nonlinear AELSTAR effect is tested with the null hypothesis:

$$
\mathrm{H}_{0}: \beta_{1}=\beta_{2}=\beta_{3}=0
$$

tested against the standard Lagrange Multiplier (LM) test following the Teräsvirta decision rule. The test statistic has an asymptotic $\chi^{2}$ distribution with $3(p+1)$ degrees of freedom and its $F$ version defined as 


$$
F_{3}=\frac{\left(\mathrm{SSR}_{0}-\mathrm{SSR}_{1}\right) / 3(p+1)}{\mathrm{SSR}_{1} /(N-4(p+1))}
$$

where $p$ is the order of the autoregression, $N$ is the sample size, and $\mathrm{SSR}_{0}$ and $\mathrm{SSR}_{1}$ are the residual sum of squares from the linear and nonlinear specifications, respectively.

Testing nonlinearity in the proposed AELSTAR model is similar to that of LSTAR since the orders of $y_{t-d}$ in the auxiliary model are up to 3 . In a similar manner to the Teräsvirtá (1994) Procedure (TP), Escribano and Jordá (2001) Procedure (EJP) can also be generalized from the test for LSTAR nonlinearity which applied second-order Taylor series expansion of the transition function. In that case, obtained in a similar fashion, the auxiliary regression model is

$$
\begin{aligned}
y_{t}= & \phi_{1}^{\prime} \tilde{y}_{t}^{(p)}+\beta_{1}^{\prime} \tilde{y}_{t}^{(p)}\left|\epsilon_{t-d}\right|+\beta_{2}^{\prime} \tilde{y}_{t}^{(p)}\left(\left|\epsilon_{t-d}\right|\right)^{2}+\beta_{3}^{\prime} \tilde{y}_{t}^{(p)}\left(\left|\epsilon_{t-d}\right|\right)^{3} \\
& +\beta_{4}^{\prime} \tilde{y}_{t}^{(p)}\left(\left|\epsilon_{t-d}\right|\right)^{4}+\tilde{\epsilon}_{t}
\end{aligned}
$$

The null hypothesis of linearity is then given as

$$
\mathrm{H}_{0}: \beta_{1}=\beta_{2}=\beta_{3}=\beta_{4}=0
$$

which is tested against the standard Lagrange Multiplier (LM) test using the EJP decision rule. The test statistic has an asymptotic $\chi^{2}$ distribution with $4(p+1)$ degrees of freedom and its $F$ version defined as

$$
F_{4}=\frac{\left(\mathrm{SSR}_{0}-\mathrm{SSR}_{1}\right) / 4(p+1)}{\mathrm{SSR}_{1} /(N-5(p+1))},
$$

where $p$ is the order of the autoregression, $N$ is the sample size, and $\mathrm{SSR}_{0}$ and $\mathrm{SSR}_{1}$ are the residual sum of squares.

\section{The QLSTAR Transition Function}

For the QLSTAR transition function, the third order Taylor series approximation around the null hypothesis, $\gamma=0$, is 


\section{LOGISTIC SMOOTH TRANSITION}

$$
\begin{aligned}
\left.\mathrm{F}\left(\epsilon_{t-d} ; \gamma, c\right) \approx \mathrm{F}\left(y_{t-d} ; \gamma, c\right)\right|_{\gamma=0}+\left.\gamma \frac{\partial \mathrm{F}\left(y_{t-d} ; \gamma, c\right)}{\partial \gamma \cdot 1 !}\right|_{\gamma=0} \\
+\left.\gamma^{2} \frac{\partial^{2} \mathrm{~F}\left(y_{t-d} ; \gamma, c\right)}{\partial \gamma^{2} .1 !}\right|_{\gamma=0}+\left.\gamma^{3} \frac{\partial^{3} \mathrm{~F}\left(y_{t-d} ; \gamma, c\right)}{\partial \gamma^{3} .1 !}\right|_{\gamma=0}
\end{aligned}
$$

where

$$
\begin{aligned}
& \text { a) } \mathrm{F}\left(y_{t-d} ; \gamma, c\right)=\left\{1+\exp \left[-\gamma\left(y_{t-d}+b y_{t-d}-c\right)\right]\right\}^{-1}-\frac{1}{2},\left.\mathrm{~F}\left(y_{t-d} ; \gamma, c\right)\right|_{\gamma=0}=0 \\
& \text { b) } \frac{\partial \mathrm{F}\left(y_{t-d} ; \gamma, c\right)}{\partial \gamma}=\left(\left(y_{t-d}^{2}+b y_{t-d}-c\right) \exp \left[-\gamma\left(y_{t-d}^{2}+b y_{t-d}-c\right)\right]\right) \\
& \times\left(\left\{1+\exp \left[-\gamma\left(y_{t-d}^{2}+b y_{t-d}-c\right)\right]\right\}^{2}\right)^{-1}, \\
& \left.\frac{\partial \mathrm{F}\left(y_{t-d} ; \gamma, c\right)}{\partial \gamma}\right|_{\gamma=0}=\frac{1}{4}\left(y_{t-d}^{2}+b y_{t-d}-c\right) \\
& \text { c) } \frac{\partial^{2} \mathrm{~F}\left(y_{t-d} ; \gamma, c\right)}{\partial \gamma^{2}}=2\left(y_{t-d}^{2}+b y_{t-d}-c\right)^{2}\left\{1+\exp \left[-\gamma\left(y_{t-d}^{2}+b y_{t-d}-c\right)\right]\right\}^{-3} \times \\
& \left(\exp \left[-\gamma\left(y_{t-d}^{2}+b y_{t-d}-c\right)\right]\right)-\left(y_{t-d}^{2}+b y_{t-d}-c\right)^{2} \times \\
& \exp \left[-\gamma\left(y_{t-d}^{2}+b y_{t-d}-c\right)\right]\left\{1+\exp \left[-\gamma\left(y_{t-d}^{2}+b y_{t-d}-c\right)\right]\right\}^{-2}, \\
& \left.\frac{\partial^{2} \mathrm{~F}\left(y_{t-d} ; \gamma, c\right)}{\partial \gamma^{2}}\right|_{\gamma=0}=0 \\
& \frac{\partial^{3} \mathrm{~F}\left(y_{t-d} ; \gamma, c\right)}{\partial \gamma^{3}}=6\left(y_{t-d}^{2}+b y_{t-d}-c\right)^{3}\left\{1+\exp \left[-\gamma\left(y_{t-d}^{2}+b y_{t-d}-c\right)\right]\right\}^{-4} \times \\
& \left(\exp \left[-\gamma\left(y_{t-d}^{2}+b y_{t-d}-c\right)\right]\right)^{3}-2\left(y_{t-d}^{2}+b y_{t-d}-c\right)^{3} \times \\
& \exp \left[-\gamma\left(y_{t-d}^{2}+b y_{t-d}-c\right)\right]\left\{1+\exp \left[-\gamma\left(y_{t-d}^{2}+b y_{t-d}-c\right)\right]\right\}^{-3} \\
& +\left(y_{t-d}^{2}+b y_{t-d}-c\right)^{3} \exp \left[-\gamma\left(y_{t-d}^{2}+b y_{t-d}-c\right)\right] \times \\
& \text { d) } \\
& \left\{1+\exp \left[-\gamma\left(y_{t-d}^{2}+b y_{t-d}-c\right)\right]\right\}^{-2}-2\left(y_{t-d}^{2}+b y_{t-d}-c\right)^{3} \times
\end{aligned}
$$




$$
\begin{gathered}
\left(\exp \left[-\gamma\left(y_{t-d}^{2}+b y_{t-d}-c\right)\right]\right)^{2}\left\{1+\exp \left[-\gamma\left(y_{t-d}^{2}+b y_{t-d}-c\right)\right]\right\}^{-3} \\
\left.\frac{\partial^{3} \mathrm{~F}\left(y_{t-d} ; \gamma, c\right)}{\partial \gamma^{3} \cdot 3 !}\right|_{\gamma=0}=\frac{1}{8}\left(y_{t-d}^{2}+b y_{t-d}-c\right)^{3}
\end{gathered}
$$

Putting steps (a-d) in (16),

$$
\begin{aligned}
& \mathrm{F}\left(y_{t-d} ; \gamma, c\right)= 0+\gamma \frac{1}{4} \frac{y_{t-d}^{2}+b y_{t-d}-c}{1 !}+\frac{0}{2}+\gamma^{3} \frac{1}{8} \frac{\frac{1}{4}\left(y_{t-d}^{2}+b y_{t-d}-c\right)^{3}}{3 !} \\
&= \frac{1}{4} \gamma\left(y_{t-d}^{2}+b y_{t-d}-c\right)+\frac{1}{48} \gamma^{3}\left(y_{t-d}^{2}+b y_{t-d}-c\right)^{3} \\
&=-(\left.\frac{1}{4} c \gamma+\frac{1}{48} \frac{\gamma^{3} c^{3}}{16}\right)+\left(\frac{1}{4} \gamma+\frac{\gamma^{3} c^{3}}{16}\right)\left(y_{t-d}^{2}+b y_{t-d}\right) \\
&-\left(\frac{1}{16} c \gamma^{3}\left(y_{t-d}^{2}+b y_{t-d}\right)^{2}\right)+\left(\frac{1}{48} \gamma^{3}\left(y_{t-d}^{2}+b y_{t-d}\right)^{3}\right) \\
& \mathrm{F}\left(y_{t-d} ; \gamma, c\right)=-\frac{1}{48} c \gamma\left(c^{2} \gamma^{2}+12\right)+\frac{1}{16} b \gamma\left(4+c^{2} \gamma^{2}\right) y_{t-d} \\
&+\frac{1}{16} \gamma\left(4+c^{2} \gamma^{2}-b^{2} c \gamma^{2}\right) y_{t-d}^{2}+\frac{1}{48} b \gamma^{3}\left(b^{2}-6 c\right) y_{t-d}^{3} \\
&+\frac{1}{16} b \gamma^{3}\left(b^{2}-c\right) y_{t-d}^{4}+\frac{1}{16} b \gamma^{3} y_{t-d}^{5}+\frac{1}{48} \gamma^{3} y_{t-d}^{6}
\end{aligned}
$$

The two-regime STAR model in (1) is equivalent to the LSTAR model

$$
y_{t}=\phi_{1}^{\prime} \tilde{y}_{t}^{(p)}+\phi^{\prime} \tilde{y}_{t}^{(p)} \mathrm{F}\left(y_{t-d} ; \gamma, c\right)+\epsilon_{t}
$$

with the transition function replaced by QLSTAR function. Substituting the approximated QLSTAR function in (18) in the QLSTAR model above gives 


\section{LOGISTIC SMOOTH TRANSITION}

$$
\begin{aligned}
y_{t}= & \phi_{1}^{\prime} \tilde{y}_{t}^{(p)}+\phi^{\prime} \tilde{y}_{t}^{(p)}\left[-\frac{1}{48} c \gamma\left(c^{2} \gamma^{2}+12\right)+\frac{1}{16} b \gamma\left(4+c^{2} \gamma^{2}\right) y_{t-d}\right. \\
& +\frac{1}{16} \gamma\left(4+c^{2} \gamma^{2}-b^{2} c \gamma^{2}\right) y_{t-d}^{2}+\frac{1}{48} b \gamma^{3}\left(b^{2}-6 c\right) y_{t-d}^{3} \\
& \left.+\frac{1}{16} \frac{1}{4} b \gamma^{3}\left(b^{2}-c\right) y_{t-d}^{4}+\frac{1}{16} b \gamma^{3} y_{t-d}^{5}+\frac{1}{48} \gamma^{3} y_{t-d}^{6}\right]+\epsilon_{t}
\end{aligned}
$$

which is equivalent to the auxiliary regression model

$$
\begin{aligned}
y_{t} & =\gamma_{0}^{\prime} \tilde{y}_{t}^{(p)}+\gamma_{1}^{\prime} \tilde{y}_{t}^{(p)} y_{t-d}+\gamma_{2}^{\prime} \tilde{y}_{t}^{(p)} y_{t-d}^{2}+\gamma_{3}^{\prime} \tilde{y}_{t}^{(p)} y_{t-d}^{3}+\gamma_{4}^{\prime} \tilde{y}_{t}^{(p)} y_{t-d}^{4}+\gamma_{5}^{\prime} \tilde{y}_{t}^{(p)} y_{t-d}^{5} \\
& +\gamma_{6}^{\prime} \tilde{y}_{t}^{(p)} y_{t-d}^{6}+\vartheta_{t}
\end{aligned}
$$

Because $\gamma_{i}(i=0, \ldots, 6)$ do not exist in real sense since they are parameters of the model, we therefore compute the corresponding estimates for them based on the regression model

$$
\begin{aligned}
y_{t} & =\beta_{0}^{\prime} \tilde{y}_{t}^{(p)}+\beta_{1}^{\prime} \tilde{y}_{t}^{(p)} y_{t-d}+\beta_{2}^{\prime} \tilde{y}_{t}^{(p)} y_{t-d}^{2}+\beta_{3}^{\prime} \tilde{y}_{t}^{(p)} y_{t-d}^{3}+\beta_{4}^{\prime} \tilde{y}_{t}^{(p)} y_{t-d}^{4}+\beta_{5}^{\prime} \tilde{y}_{t}^{(p)} y_{t-d}^{5} \\
& +\beta_{6}^{\prime} \tilde{y}_{t}^{(p)} y_{t-d}^{6}+\vartheta_{t}
\end{aligned}
$$

which can be re-written as

$$
\begin{aligned}
\vartheta_{t} & =\beta_{0}^{\prime} \tilde{y}_{t}^{(p)}+\beta_{1}^{\prime} \tilde{y}_{t}^{(p)} y_{t-d}+\beta_{2}^{\prime} \tilde{y}_{t}^{(p)} y_{t-d}^{2}+\beta_{3}^{\prime} \tilde{y}_{t}^{(p)} y_{t-d}^{3}+\beta_{4}^{\prime} \tilde{y}_{t}^{(p)} y_{t-d}^{4} \\
& +\beta_{5}^{\prime} \tilde{y}_{t}^{(p)} y_{t-d}^{5}+\varsigma_{t}
\end{aligned}
$$

where $\beta_{i}^{\prime} y_{t}^{(p)}, i=1,2,3$ are functions of $b, c$, and $\gamma$. Hence all the 6 terms are duly represented in the model. The model is QLSTAR if at least one of $\beta_{i}^{\prime}$ is not zero when the auxiliary regression is performed. So the regression above is performed by regressing $\vartheta_{t}$ on the series of regressors $\tilde{y}_{t}^{(p)}$ and $y_{t-d}^{i},(i=1, \ldots, 6)$. Nonlinear QLSTAR is then tested based on the null hypothesis:

$$
\mathrm{H}_{0}: \beta_{1}=\beta_{2}=\beta_{3}=\beta_{4}=\beta_{5}=\beta_{6}=0
$$




\section{YAYA \& SHITTU}

which can be tested against standard Lagrange Multiplier (LM) test. The test statistic has an asymptotic $\chi^{2}$ distribution with $6(p+1)$ degrees of freedom and its $F$ version defined as

$$
F_{6}=\frac{\left(\mathrm{SSR}_{0}-\mathrm{SSR}_{1}\right) / 6(p+1)}{\mathrm{SSR}_{1} /(N-7(p+1))}
$$

The QLSTAR nonlinearity is then detected in the series once one of $\beta_{j},(j=1, \ldots, 6)$ is significantly different from zero in the auxiliary regression model in (21). The QLSTAR model is then specified when the level of significance of parameters $\beta_{1}$, $\beta_{3}$, and $\beta_{6}$ are higher than that of $\beta_{2}, \beta_{4}$, and $\beta_{6}$. The counterpart, Quadratic ESTAR (QESTAR), is then chosen once there EW contrary results. Testing QLSTAR nonlinearity using Escribano and Jordá (2001) is much more straightforward. Linearity is established once the betas are zeroed. Once there is default in one, the decision rule of Escribano and Jordá (2001) is applied. Then apply the revised decision rule

$$
\begin{aligned}
& \mathrm{H}_{0 \text { QLSTAR }}: \beta_{1}=\beta_{3}=\beta_{5}=0 \\
& \mathrm{H}_{0 \text { QESTAR }}: \beta_{2}=\beta_{4}=\beta_{6}=0
\end{aligned}
$$

Therefore, rejecting $\mathrm{H}_{\text {OQLSTAR }}$ and failing to reject $\mathrm{H}_{\text {OQESTAR }}$ points to QLSTAR model. Also, rejecting $\mathrm{H}_{0 \mathrm{QESTAR}}$ and failing to reject $\mathrm{H}_{0 \mathrm{QLSTAR}}$ suggests a QESTAR model. In addition, if the minimum $p$-value corresponds to $F_{6}$, select QLSTAR and, if the minimum $p$-value corresponds to $F_{6}$, select QESTAR model.

\section{Monte Carlo (MC) Simulations}

Due to the unavailability of the structural and distributional properties of the parameters of the STAR models as a result of unknown regularities conditions, Monte Carlo's simulation approach is then used to study the behaviors of some parameters in the model via the model selection procedures. The accuracy of the TP and EJP approaches in selecting between the two types of LSTAR models is then examined. The correct selection rate is reported as a proportion per 1000 replications for which linearity was first rejected at $95 \%$ confidence level. The robustness of the selection procedures is also tested by considering non-zero threshold values, $c \neq 0$ that make the model to be asymmetric. 


\section{LOGISTIC SMOOTH TRANSITION}

The program for the simulation is set under the OxGAUSS engine. Most nonlinear simulation and estimations are performed under GAUSS machines, particularly with Ox, since this helps to perform the simulations at a faster rate when compared to other software or ordinary GAUSS software. (Lin, 2001; Chan and McAleer, 2001; 2003). We first consider using the STAR Data Generating Process (DGP) used in Granger and Teräsvirta (1993), Teräsvirta, Lin, and Granger (1993), Teräsvirta (1994), Escribano, Franses, and van Dijk (1998), Escribano and Jordá (2001), Lopes and Salazar (2006), and Adebile (2007):

$$
y_{t}=1.800 y_{t-1}-1.060 y_{t-2}\left(\phi_{20}-0.900 y_{t-1}+0.795 y_{t-2}\right) F\left(s_{t} ; \gamma, c\right)+\epsilon_{t}
$$

where $\epsilon_{t} \sim \mathrm{N}\left(0,0.02^{2}\right)$ and $\epsilon_{t} \sim \mathrm{N}\left(0,0.10^{2}\right)$ for the STAR specification. The values for $\phi_{20}$ are set as $\phi_{20}=\{0.0,0.2\}$. The STAR DGP in (25) is suggested due to the fact that it has been used over and over by researchers. Probing into the DGP, when the transition function $\mathrm{F}\left(s_{t} ; \gamma, c\right)=0$, the system is in the lower regime and gives a linear AR model with the characteristic equation $1.06 B^{2}-1.80 B+1=0$, which has roots $|0.849 \pm 0.472|$ in the complex plane and the modulus of the complex root is 0.971 . The real root is 0.849 , which is less than unity; this implies nonstationarity of the realized time series process. This may cause an explosion unless stationarity is imposed on the nonlinear part of the DGP, and $y_{t}$ will have the tendency to adjust to more stable parts of the state space.

Teräsvirta (1994) and Escribano et al. (1998) supported this assertion. Also, when $\mathrm{F}\left(s_{t} ; \gamma, c\right)=1$, the system is in the upper regime and gives the AR model $y_{t}=\phi_{20}+0.900 y_{t-1}-0.265 y_{t-2}+\epsilon_{t}$. Because $\phi_{20}$ has values 0.0 and 0.2 , we therefore have two characteristic equations: $0.265 B^{2}-0.900 B+1=0$ and $0.265 B^{2}-0.900 B+0.8=0$, which give the complex roots $|1.698 \pm 0.943|$ and $|1.698 \pm 0.368|$ with the moduli of 1.942 and 1.737 , respectively. These roots lie outside the unit circle, and this will control the system to realize stationary series. These are the motives for using the GDP. It is obvious to see that the properties of time series to be generated will then depend on the relative magnitude of $\phi_{20}$ and $c$ as they jointly determine the value of $y_{t}$ and its instability and stability (Escribano et al., 1998).

Occasionally, the software simulates values $y_{t}<c$ which makes the linear AR model to be explosive, and this point is not common in real life situation (Escribano \& Jordá, 2001). A burn-in of 100 observations shields the experiments against a potential dependence on starting values and, after making allowance to discard these, we proceed in the simulations. It is also noted that higher values of the slope parameter, $\gamma$, will cause the power of the two selection procedures to be closed to 


\section{YAYA \& SHITTU}

each other, and this makes the nonlinearity to be sharp and significant. Therefore this will make the discrimination between the two models to be close to each other (Escribano \& Jordá, 2001). So we also consider setting $\gamma=\{1,10,100\}$ and $c=\{0.0,0.2,0.5,1.0\}$ in the transition functions.

The DGPs are LSTAR with the transition functions

$$
\begin{gathered}
\mathrm{F}\left(s_{t} ; \gamma, c\right) \equiv \mathrm{F}\left(y_{t-d} ; \gamma, c\right)=\frac{1}{1+\exp \left[-\gamma\left(y_{t-d}-c\right)\right]} \\
\mathrm{F}\left(\epsilon_{t} ; \gamma, c\right) \equiv \mathrm{F}\left(\epsilon_{t-d} ; \gamma, c\right)=\frac{1}{1+\exp \left[-\gamma\left(\epsilon_{t-d}-c\right)\right]} \\
\mathrm{F}\left(s_{t} ; \gamma, c\right) \equiv \mathrm{F}\left(y_{t-d} ; \gamma, c\right)=\frac{1}{1+\exp \left[-\gamma\left(y_{t-d}^{2}+\epsilon_{t-d}-c\right)\right]}
\end{gathered}
$$

Relative frequencies of the models specification are computed and presented on every 1000 replications and across sample sizes $N=\{50,100,200,500,1000\}$. The cells report the number of times a variant of LSTAR model is selected at $5 \%$ nominal significant level in every 1000 replications.

The results are presented in Tables 1-6 below. From Table 1, $\phi_{20}$, the nonlinear component of the DGP realizes real values though the linear component is still complex. The QLSTAR model compares favorably well with the LSTAR based on the specification tests, TP and EJP. Improvement in selection frequencies is seen as sample sizes increase, therefore specification of models is consistent with sample size. TP outperforms EJP when the threshold, $c$, is marginally different from zero ( say $c=0.2$ ). Comparison of the models shows that the proposed AELSTAR and QLSTAR models seem to realize lower frequencies when compared with the original LSTAR model. This implies that the data generated by the proposed models resembled ESTAR, which is a symmetric series, and this may be clearer when the variation in the series is increased.

With increased standard deviation $\sigma=0.1$, more selection frequencies of selection are computed for the variants of the model. Unlike the results in Table 1, here the frequencies are computed for the heteroscedastic versions of the models. This implies that the level of variations in the time series a direct the specification of the models. In the selection of variants of LSTAR models, the TP dominates EJP in discriminating between the two types of STAR models as indicated in the frequencies computed based on the two procedures for each of the LSTAR models. Also, the frequencies computed by the variants of LSTAR are smaller than the values realized by the original LSTAR model, which is indication that the 


\section{LOGISTIC SMOOTH TRANSITION}

AELSTAR and QLSTAR models detect symmetric time series. The selection frequencies imply higher frequencies computed for the ESTAR models.

In Table 2, the TP outperforms the EJP at different simulation points. TP is also seen to be more consistent with increasing sample sizes. Matrix inversion problems were also reported during the simulation due to lower variation in the series. Increasing the parameter $\phi_{20}=0.0$ to $\phi_{20}=0.2$ has caused an increase in the model selection frequencies. Since this parameter directs the stationarity level of the realized series, it then implies that stationarity has a relationship with nonlinearity of the series. For model comparison, the results here follow that of Table 1, only that the improvement in the symmetry as indicated by the proposed transition functions is not as significant as the results given in Table 1 .

From Table 3, with increased in transition speed $\gamma=10$, nonlinearity is clearer due to more points that are computed for frequencies of selection. QLSTAR model competes favorably well with the LSTAR. Increase in transition speed also led to the computation of the GARCH component in the model. This implies that the GARCH effect is much felt in the series when nonlinearity is sharper. EJP is more consistent in selecting the variants of the LSTAR model up to $c=0.5$ and $N=1000$. TP is consistent up to $c=0.2$ and $N=1000$ for LSTAR and QLSTAR models. EJP is seen to dominate TP in LSTAR and QLSTAR versions of the models, whereas in AELSTAR models, TP dominates EJP.

In Table 4, both TP and EJP compete well in selecting variants of AELSTAR and QLSTAR models. More frequencies are computed for the AELSTAR model, and this favors the selection of the LSTAR model. The proposed models realized symmetric time series as indicated in the lower frequencies realized for the LSTAR models by the two specification procedures.

With nonlinearity further increased to transition speed $\gamma=100$, more selection frequencies are generated. EJP is more sensitive to selection of LSTAR and QLSTAR models, while TP is sensitive to selecting only the AELST AR model. In selecting the LSTAR model, only EJP is consistent with sample sizes throughout. The results indicated that symmetric time series are realized by the proposed models as indicated by the lower frequencies computed for the LSTAR models which is known to be asymmetric. 


\section{YAYA \& SHITTU}

Table 1. Selection frequencies of variants of LSTAR model at $\gamma=1, \phi_{20}=0.0$ for $\epsilon_{t} \sim N\left(0,0.02^{2}\right)$ and $\epsilon_{t} \sim N\left(0,0.10^{2}\right)$ for STAR Specifications

LSTAR

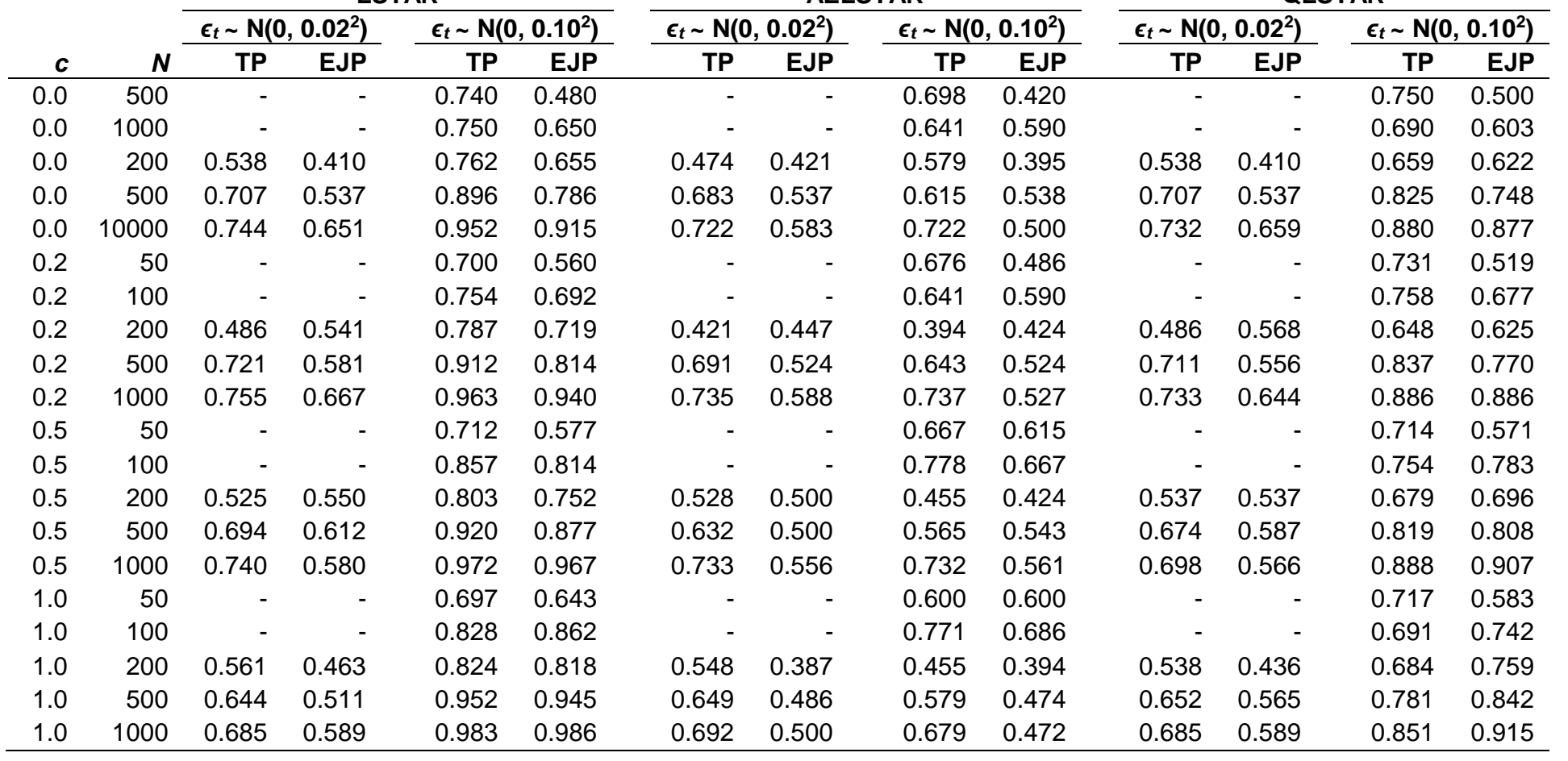




\section{LOGISTIC SMOOTH TRANSITION}

Table 2. Selection frequencies of variants of LSTAR model at $\gamma=1, \phi_{20}=0.2$ for $\epsilon_{t} \sim \mathrm{N}\left(0,0.02^{2}\right)$ and $\epsilon_{t} \sim \mathrm{N}\left(0,0.10^{2}\right)$ for STAR Specifications

\begin{tabular}{|c|c|c|c|c|c|c|c|c|c|c|c|c|c|}
\hline \multirow[b]{3}{*}{$c$} & \multirow[b]{3}{*}{$N$} & \multicolumn{4}{|c|}{ LSTAR } & \multicolumn{4}{|c|}{ AELSTAR } & \multicolumn{4}{|c|}{ QLSTAR } \\
\hline & & $\epsilon_{t} \sim \mathrm{N}(\mathrm{C}$ & $\left.0.02^{2}\right)$ & \multicolumn{2}{|c|}{$\epsilon_{t} \sim \mathrm{N}\left(0,0.10^{2}\right)$} & \multicolumn{2}{|c|}{$\epsilon_{t} \sim \mathrm{N}\left(0,0.02^{2}\right)$} & \multicolumn{2}{|c|}{$\epsilon_{t} \sim \mathrm{N}\left(0,0.10^{2}\right)$} & \multicolumn{2}{|c|}{$\epsilon_{t} \sim \mathrm{N}\left(0,0.02^{2}\right)$} & \multicolumn{2}{|c|}{$\epsilon_{t} \sim \mathrm{N}\left(0,0.10^{2}\right)$} \\
\hline & & TP & EJP & TP & EJP & TP & EJP & TP & EJP & TP & EJP & TP & EJP \\
\hline 0.0 & 500 & - & - & 0.721 & 0.465 & - & - & 0.658 & 0.421 & - & - & 0.589 & 0.464 \\
\hline 0.0 & 1000 & - & - & 0.768 & 0.518 & - & - & 0.686 & 0.486 & - & - & 0.726 & 0.493 \\
\hline 0.0 & 200 & 0.595 & 0.500 & 0.778 & 0.583 & 0.526 & 0.526 & 0.568 & 0.522 & 0.707 & 0.463 & 0.745 & 0.480 \\
\hline 0.0 & 500 & 0.692 & 0.385 & 0.893 & 0.508 & 0.700 & 0.550 & 0.707 & 0.683 & 0.721 & 0.372 & 0.909 & 0.514 \\
\hline 0.0 & 10000 & 0.750 & 0.591 & 0.933 & 0.601 & 0.767 & 0.488 & 0.604 & 0.583 & 0.700 & 0.600 & 0.973 & 0.496 \\
\hline 0.2 & 50 & - & - & 0.710 & 0.421 & - & - & 0.667 & 0.500 & - & - & 0.611 & 0.429 \\
\hline 0.2 & 100 & - & - & 0.737 & 0.491 & - & - & 0.737 & 0.500 & - & - & 0.756 & 0.488 \\
\hline 0.2 & 200 & 0.625 & 0.550 & 0.805 & 0.61 & 0.421 & 0.579 & 0.459 & 0.595 & 0.659 & 0.561 & 0.744 & 0.529 \\
\hline 0.2 & 500 & 0.732 & 0.390 & 0.928 & 0.582 & 0.683 & 0.561 & 0.659 & 0.705 & 0.690 & 0.357 & 0.907 & 0.534 \\
\hline 0.2 & 1000 & 0.745 & 0.588 & 0.944 & 0.628 & 0.800 & 0.450 & 0.761 & 0.478 & 0.708 & 0.631 & 0.965 & 0.510 \\
\hline 0.5 & 50 & - & - & 0.761 & 0.522 & - & - & 0.703 & 0.432 & - & - & 0.644 & 0.508 \\
\hline 0.5 & 100 & - & - & 0.772 & 0.474 & - & - & 0.778 & 0.417 & - & - & 0.774 & 0.560 \\
\hline 0.5 & 200 & 0.657 & 0.514 & 0.826 & 0.616 & 0.545 & 0.545 & 0.529 & 0.529 & 0.625 & 0.475 & 0.739 & 0.556 \\
\hline 0.5 & 500 & 0.745 & 0.426 & 0.914 & 0.686 & 0.628 & 0.535 & 0.698 & 0.721 & 0.698 & 0.528 & 0.900 & 0.537 \\
\hline 0.5 & 1000 & 0.732 & 0.500 & 0.947 & 0.736 & 0.750 & 0.523 & 0.708 & 0.438 & 0.774 & 0.613 & 0.955 & 0.557 \\
\hline 1.0 & 50 & - & - & 0.780 & 0.560 & - & - & 0.567 & 0.600 & - & - & 0.787 & 0.591 \\
\hline 1.0 & 100 & - & - & 0.736 & 0.605 & - & - & 0.765 & 0.618 & - & - & 0.739 & 0.635 \\
\hline 1.0 & 200 & 0.634 & 0.537 & 0.819 & 0.624 & 0.500 & 0.600 & 0.441 & 0.559 & 0.636 & 0.477 & 0.727 & 0.556 \\
\hline 1.0 & 500 & 0.659 & 0.500 & 0.935 & 0.791 & 0.684 & 0.605 & 0.610 & 0.488 & 0.642 & 0.434 & 0.871 & 0.595 \\
\hline 1.0 & 1000 & 0.696 & 0.551 & 0.980 & 0.858 & 0.719 & 0.386 & 0.722 & 0.463 & 0.653 & 0.431 & 0.920 & 0.643 \\
\hline
\end{tabular}




\section{YAYA \& SHITTU}

Table 3. Selection frequencies of variants of LSTAR model at $\gamma=10, \phi_{20}=0.0$ for $\epsilon_{t} \sim \mathrm{N}\left(0,0.02^{2}\right)$ and $\epsilon_{t} \sim \mathrm{N}\left(0,0.10^{2}\right)$ for STAR Specifications

\begin{tabular}{|c|c|c|c|c|c|c|c|c|c|c|c|c|c|}
\hline \multirow[b]{3}{*}{$c$} & \multirow[b]{3}{*}{$N$} & \multicolumn{4}{|c|}{ LSTAR } & \multicolumn{4}{|c|}{ AELSTAR } & \multicolumn{4}{|c|}{ QLSTAR } \\
\hline & & \multicolumn{2}{|c|}{$\epsilon_{t} \sim \mathrm{N}\left(0,0.02^{2}\right)$} & \multicolumn{2}{|c|}{$\epsilon_{t} \sim \mathrm{N}\left(0,0.10^{2}\right)$} & \multicolumn{2}{|c|}{$\epsilon_{t} \sim \mathrm{N}\left(0,0.02^{2}\right)$} & \multicolumn{2}{|c|}{$\epsilon_{t} \sim \mathrm{N}\left(0,0.10^{2}\right)$} & \multicolumn{2}{|c|}{$\epsilon_{t} \sim \mathrm{N}\left(0,0.02^{2}\right)$} & \multicolumn{2}{|c|}{$\epsilon_{t} \sim \mathrm{N}\left(0,0.10^{2}\right)$} \\
\hline & & TP & EJP & TP & EJP & TP & EJP & TP & EJP & TP & EJP & TP & EJP \\
\hline 0.0 & 500 & - & - & 0.922 & 0.962 & - & - & 0.698 & 0.4199 & - & - & 0.750 & 0.500 \\
\hline 0.0 & 1000 & - & - & 0.973 & 0.994 & - & - & 9 & & - & - & 0.690 & 0.603 \\
\hline 0.0 & 200 & 0.918 & 0.863 & 0.995 & 1.000 & 0.575 & 0.450 & 0.641 & 0.590 & 0.881 & 0.852 & 0.659 & 0.622 \\
\hline 0.0 & 500 & 0.986 & 0.973 & 1.000 & 1.000 & 0.684 & 0.553 & 0.579 & 0.395 & 0.983 & 0.970 & 0.825 & 0.748 \\
\hline 0.0 & 10000 & 1.000 & 0.993 & 1.000 & 1.000 & 0.522 & 0.478 & 0.615 & 0.538 & 0.999 & 0.992 & 0.880 & 0.870 \\
\hline 0.2 & 50 & - & - & 0.870 & 0.966 & - & - & 0.722 & 0.500 & - & - & 0.731 & 0.519 \\
\hline 0.2 & 100 & 0.897 & 0.932 & 0.928 & 0.994 & 0.585 & 0.463 & 0.676 & 0.486 & 0.875 & 0.913 & 0.758 & 0.677 \\
\hline 0.2 & 200 & 0.959 & 0.982 & 0.979 & 1.000 & 0.629 & 0.514 & 0.641 & 0.590 & 0.941 & 0.974 & 0.648 & 0.625 \\
\hline 0.2 & 500 & 0.996 & 1.000 & 1.000 & 1.000 & 0.608 & 0.431 & 0.394 & 0.424 & 0.993 & 0.997 & 0.837 & 0.770 \\
\hline 0.2 & 1000 & 1.000 & 1.000 & 1.000 & 1.000 & 0.612 & 0.531 & 0.643 & 0.524 & 1.000 & 1.000 & 0.886 & 0.886 \\
\hline 0.5 & 50 & - & 0.964 & 0.773 & 0.887 & 0.700 & 0.550 & 0.737 & 0.526 & - & 0.944 & 0.714 & 0.571 \\
\hline 0.5 & 100 & - & 0.997 & 0.865 & 0.961 & 0.680 & 0.480 & 0.667 & 0.615 & - & 0.983 & 0.754 & 0.783 \\
\hline 0.5 & 200 & - & 1.000 & 0.936 & 0.992 & 0.700 & 0.550 & 0.778 & 0.667 & - & 0.998 & 0.679 & 0.696 \\
\hline 0.5 & 500 & - & 1.000 & 0.997 & 1.000 & 0.683 & 0.542 & 0.455 & 0.524 & - & 1.000 & 0.819 & 0.808 \\
\hline 0.5 & 1000 & - & 1.000 & 1.000 & 1.000 & 0.642 & 0.512 & 0.565 & 0.543 & - & 1.000 & 0.888 & 0.907 \\
\hline 1.0 & 50 & - & 1.000 & 0.604 & 0.894 & 0.692 & 0.481 & 0.732 & 0.561 & - & 0.997 & 0.717 & 0.583 \\
\hline 1.0 & 100 & - & 0.999 & 0.664 & 0.960 & 0.735 & 0.490 & 0.600 & 0.600 & - & 1.000 & 0.691 & 0.742 \\
\hline 1.0 & 200 & - & 1.000 & 0.763 & 0.998 & 0.667 & 0.471 & 0.771 & 0.686 & - & 1.000 & 0.684 & 0.759 \\
\hline 1.0 & 500 & - & 1.000 & 0.914 & 1.000 & 0.664 & 0.502 & 0.455 & 0.394 & - & 1.000 & 0.781 & 0.842 \\
\hline 1.0 & 1000 & - & - & 1.000 & 1.000 & 0.673 & 0.525 & 0.579 & 0.474 & - & 1.000 & 0.851 & 0.915 \\
\hline
\end{tabular}




\section{LOGISTIC SMOOTH TRANSITION}

Table 4. Selection frequencies of variants of LSTAR model at $\gamma=10, \phi_{20}=0.2$ for $\epsilon_{t} \sim \mathrm{N}\left(0,0.02^{2}\right)$ and $\epsilon_{t} \sim \mathrm{N}\left(0,0.10^{2}\right)$ for STAR Specifications

\begin{tabular}{|c|c|c|c|c|c|c|c|c|c|c|c|c|c|}
\hline \multirow[b]{3}{*}{$c$} & \multirow[b]{3}{*}{$N$} & \multicolumn{4}{|c|}{ LSTAR } & \multicolumn{4}{|c|}{ AELSTAR } & \multicolumn{4}{|c|}{ QLSTAR } \\
\hline & & \multicolumn{2}{|c|}{$\epsilon_{t} \sim \mathrm{N}\left(0,0.02^{2}\right)$} & \multicolumn{2}{|c|}{$\epsilon_{t} \sim \mathrm{N}\left(0,0.10^{2}\right)$} & \multicolumn{2}{|c|}{$\epsilon_{t} \sim \mathrm{N}\left(0,0.02^{2}\right)$} & \multicolumn{2}{|c|}{$\epsilon_{t} \sim \mathrm{N}\left(0,0.10^{2}\right)$} & \multicolumn{2}{|c|}{$\epsilon_{t} \sim \mathrm{N}\left(0,0.02^{2}\right)$} & \multicolumn{2}{|c|}{$\epsilon_{t} \sim \mathrm{N}\left(0,0.10^{2}\right.$} \\
\hline & & TP & EJP & TP & EJP & TP & EJP & TP & EJP & TP & EJP & TP & EJP \\
\hline 0. & 500 & - & - & 0.776 & 0.531 & - & - & 0.604 & 0.566 & - & - & 0.723 & 0.409 \\
\hline 0. & 1000 & - & - & 0.843 & 0.585 & - & - & 0.627 & 0.627 & - & - & 0.758 & 0.532 \\
\hline 0. & 200 & - & - & 0.842 & 0.614 & - & - & 0.577 & 0.627 & - & - & 0.832 & 0.589 \\
\hline 0. & 500 & - & - & 0.854 & 0.776 & 0.830 & 0.616 & 0.731 & 0.737 & - & - & 0.821 & 0.758 \\
\hline 0. & 1000 & - & - & 0.888 & 0.904 & 0.830 & 0.616 & 0.809 & 0.789 & - & - & 0.843 & 0.870 \\
\hline 0. & 50 & - & - & 0.775 & 0.598 & - & - & 0.484 & 0.453 & - & - & 0.706 & 0.557 \\
\hline 0. & 100 & - & - & 0.912 & 0.616 & 0.605 & 0.579 & 0.600 & 0.537 & - & - & 0.904 & 0.565 \\
\hline 0. & 200 & - & - & 0.974 & 0.691 & 0.667 & 0.667 & 0.411 & 0.492 & - & - & 0.963 & 0.586 \\
\hline 0. & 500 & - & - & 0.999 & 0.820 & 0.580 & 0.540 & 0.475 & 0.660 & - & - & 0.989 & 0.709 \\
\hline 0. & 1000 & 0.754 & 0.492 & 1.000 & 0.923 & 0.661 & 0.597 & 0.480 & 0.724 & - & - & 0.993 & 0.787 \\
\hline 0. & 50 & 0.794 & 0.815 & 0.724 & 0.686 & 0.661 & 0.597 & 0.620 & 0.480 & - & - & 0.745 & 0.670 \\
\hline 0. & 100 & 0.911 & 0.931 & 0.810 & 0.758 & 0.667 & 0.453 & 0.703 & 0.520 & - & - & 0.849 & 0.739 \\
\hline 0. & 200 & 0.974 & 0.982 & 0.910 & 0.855 & 0.705 & 0.558 & 0.696 & 0.532 & - & - & 0.933 & 0.843 \\
\hline 0. & 500 & 0.999 & 0.999 & 0.988 & 0.964 & 0.679 & 0.544 & 0.672 & 0.523 & 0.951 & 0.583 & 0.969 & 0.961 \\
\hline 0. & 1000 & 1.000 & 1.000 & 0.988 & 0.964 & 0.648 & 0.516 & 0.493 & 0.658 & 0.991 & 0.659 & 0.991 & 0.990 \\
\hline 1. & 50 & 0.678 & 0.938 & - & 0.722 & 0.692 & 0.481 & 0.679 & 0.472 & 0.338 & 0.779 & 0.612 & 0.646 \\
\hline 1. & 100 & 0.682 & 0.982 & - & 0.780 & 0.740 & 0.500 & 0.761 & 0.522 & 0.213 & 0.851 & 0.647 & 0.718 \\
\hline 1. & 200 & 0.740 & 1.000 & - & 0.887 & 0.667 & 0.471 & 0.667 & 0.504 & 0.085 & 0.949 & 0.697 & 0.744 \\
\hline 1. & 500 & 0.806 & 1.000 & - & 0.970 & 0.664 & 0.502 & 0.674 & 0.522 & 0.009 & 0.996 & 0.766 & 0.854 \\
\hline 1. & 1000 & - & - & - & 0.996 & 0.672 & 0.525 & 0.663 & 0.521 & 0.000 & 1.000 & 0.830 & 0.919 \\
\hline
\end{tabular}




\section{YAYA \& SHITTU}

Table 5. Selection frequencies of variants of LSTAR model at $\gamma=100, \phi_{20}=0.0$ for $\epsilon_{t} \sim \mathrm{N}\left(0,0.02^{2}\right)$ and $\epsilon_{t} \sim \mathrm{N}\left(0,0.10^{2}\right)$ for STAR Specifications

\begin{tabular}{|c|c|c|c|c|c|c|c|c|c|c|c|c|c|}
\hline \multirow[b]{3}{*}{$c$} & \multirow[b]{3}{*}{$N$} & \multicolumn{4}{|c|}{ LSTAR } & \multicolumn{4}{|c|}{ AELSTAR } & \multicolumn{4}{|c|}{ QLSTAR } \\
\hline & & \multicolumn{2}{|c|}{$\epsilon_{t} \sim \mathrm{N}\left(0,0.02^{2}\right)$} & \multicolumn{2}{|c|}{$\epsilon_{t} \sim \mathrm{N}\left(0,0.10^{2}\right)$} & \multicolumn{2}{|c|}{$\epsilon_{t} \sim \mathrm{N}\left(0,0.02^{2}\right)$} & \multicolumn{2}{|c|}{$\epsilon_{t} \sim \mathrm{N}\left(0,0.10^{2}\right)$} & \multicolumn{2}{|c|}{$\epsilon_{t} \sim \mathrm{N}\left(0,0.02^{2}\right)$} & \multicolumn{2}{|c|}{$\epsilon_{t} \sim \mathrm{N}\left(0,0.10^{2}\right.$} \\
\hline & & TP & EJP & TP & EJP & TP & EJP & TP & EJP & TP & EJP & TP & EJP \\
\hline 0.0 & 500 & - & - & 0.941 & 0.989 & - & - & 0.600 & 0.511 & - & - & 0.889 & 0.985 \\
\hline 0.0 & 1000 & - & - & 0.975 & 1.000 & - & - & 0.500 & 0.455 & - & - & 0.912 & 1.000 \\
\hline 0.0 & 200 & 0.994 & 1.000 & 0.999 & 1.000 & - & - & 0.698 & 0.581 & 0.994 & 1.000 & 0.921 & 1.000 \\
\hline 0.0 & 500 & 1.000 & 1.000 & 1.000 & 1.000 & - & - & 0.611 & 0.389 & 1.000 & 1.000 & 0.976 & 1.000 \\
\hline 0.0 & 1000 & 1.000 & 1.000 & 1.000 & 1.000 & 0.500 & 0.444 & 0.725 & 0.500 & 1.000 & 1.000 & 0.995 & 1.000 \\
\hline 0.2 & 50 & - & 0.983 & 0.885 & 0.962 & 0.692 & 0.481 & 0.672 & 0.605 & 0.686 & 0.885 & 0.818 & 0.977 \\
\hline 0.2 & 100 & - & 0.968 & 0.949 & 0.991 & 0.735 & 0.510 & 0.777 & 0.658 & 0.783 & 0.968 & 0.853 & 0.994 \\
\hline 0.2 & 200 & 0.830 & 0.999 & 0.987 & 1.000 & 0.660 & 0.440 & 0.757 & 0.640 & 0.909 & 0.995 & 0.883 & 1.000 \\
\hline 0.2 & 500 & - & 1.000 & 1.000 & 1.000 & 0.715 & 0.548 & 0.699 & 0.606 & 0.991 & 1.000 & 0.951 & 1.000 \\
\hline 0.2 & 1000 & - & 1.000 & 1.000 & 1.000 & 0.635 & 0.501 & 0.650 & 0.554 & 1.000 & 1.000 & 0.984 & 1.000 \\
\hline 0.5 & 50 & - & 0.994 & 0.780 & 0.868 & 0.692 & 0.481 & 0.692 & 0.481 & 0.498 & 0.980 & 0.723 & 0.907 \\
\hline 0.5 & 100 & - & 1.000 & 0.898 & 0.960 & 0.735 & 0.510 & 0.735 & 0.510 & 0.576 & 1.000 & 0.750 & 0.962 \\
\hline 0.5 & 200 & - & 1.000 & 0.967 & 0.994 & 0.660 & 0.440 & 0.660 & 0.441 & 0.739 & 1.000 & 0.759 & 0.997 \\
\hline 0.5 & 500 & - & 1.000 & 0.999 & 1.000 & 0.768 & 0.643 & 0.776 & 0.592 & 0.900 & 1.000 & 0.827 & 1.000 \\
\hline 0.5 & 1000 & - & 1.000 & 1.000 & 1.000 & 1.000 & 0.000 & 0.663 & 0.588 & 0.978 & 1.000 & 0.894 & 1.000 \\
\hline 1.0 & 50 & - & 0.998 & 0.657 & 0.901 & 0.692 & 0.481 & 0.692 & 0.481 & 0.414 & 0.995 & 0.580 & 0.854 \\
\hline 1.0 & 100 & - & 1.000 & 0.779 & 0.973 & 0.735 & 0.510 & 0.735 & 0.510 & 0.515 & 1.000 & 0.568 & 0.936 \\
\hline 1.0 & 200 & - & 1.000 & 0.918 & 0.999 & 0.660 & 0.440 & 0.660 & 0.440 & 0.576 & 1.000 & 0.512 & 0.990 \\
\hline 1.0 & 500 & -- & 1.000 & 0.993 & 1.000 & 0.768 & 0.643 & 0.768 & 0.643 & 0.774 & 1.000 & 0.492 & 1.000 \\
\hline 1.0 & 1000 & - & 1.000 & 1.000 & 1.000 & 1.000 & 0.000 & 0.000 & 1.000 & 0.884 & 1.000 & 0.488 & 1.000 \\
\hline
\end{tabular}




\section{LOGISTIC SMOOTH TRANSITION}

Table 6. Selection frequencies of variants of LSTAR model at $\gamma=100, \phi_{20}=0.2$ for $\epsilon_{t} \sim \mathrm{N}\left(0,0.02^{2}\right)$ and $\epsilon_{t} \sim \mathrm{N}\left(0,0.10^{2}\right)$ for STAR Specifications

\begin{tabular}{|c|c|c|c|c|c|c|c|c|c|c|c|c|c|}
\hline \multirow[b]{3}{*}{$c$} & \multirow[b]{3}{*}{$N$} & \multicolumn{4}{|c|}{ LSTAR } & \multicolumn{4}{|c|}{ AELSTAR } & \multicolumn{4}{|c|}{ QLSTAR } \\
\hline & & \multicolumn{2}{|c|}{$\epsilon_{t} \sim \mathrm{N}\left(0,0.02^{2}\right)$} & \multicolumn{2}{|c|}{$\epsilon_{t} \sim \mathrm{N}\left(0,0.10^{2}\right)$} & \multicolumn{2}{|c|}{$\epsilon_{t} \sim \mathrm{N}\left(0,0.02^{2}\right)$} & \multicolumn{2}{|c|}{$\epsilon_{t} \sim \mathrm{N}\left(0,0.10^{2}\right)$} & \multicolumn{2}{|c|}{$\epsilon_{t} \sim \mathrm{N}\left(0,0.02^{2}\right)$} & \multicolumn{2}{|c|}{$\epsilon_{t} \sim \mathrm{N}\left(0,0.10^{2}\right.$} \\
\hline & & TP & EJP & TP & EJP & TP & EJP & TP & EJP & TP & EJP & TP & EJP \\
\hline 0.0 & 500 & - & - & 0.617 & 0.532 & - & - & 0.553 & 0.426 & - & - & 0.617 & 0.532 \\
\hline 0.0 & 1000 & - & - & 0.569 & 0.510 & - & - & 0.447 & 0.523 & - & - & 0.549 & 0.490 \\
\hline 0.0 & 200 & - & - & 0.733 & 0.550 & 0.917 & 0.421 & 0.679 & 0.491 & - & - & 0.705 & 0.557 \\
\hline 0.0 & 500 & - & - & 0.763 & 0.700 & 0.984 & 0.515 & 0.746 & 0.380 & - & - & 0.750 & 0.688 \\
\hline 0.0 & 1000 & - & - & 0.850 & 0.796 & 0.998 & 0.484 & 0.890 & 0.378 & - & - & 0.847 & 0.802 \\
\hline 0.2 & 50 & - & - & 0.751 & 0.643 & 0.692 & 0.491 & 0.710 & 0.571 & - & - & 0.646 & 0.653 \\
\hline 0.2 & 100 & - & - & 0.905 & 0.659 & 0.735 & 0.510 & 0.777 & 0.642 & - & - & 0.854 & 0.637 \\
\hline 0.2 & 200 & - & - & 0.979 & 0.679 & 0.660 & 0.440 & 0.747 & 0.657 & - & - & 0.933 & 0.681 \\
\hline 0.2 & 500 & - & - & 0.993 & 0.818 & 0.715 & 0.548 & 0.699 & 0.604 & - & - & 0.960 & 0.829 \\
\hline 0.2 & 1000 & - & - & 1.000 & 0.908 & 0.635 & 0.501 & 0.638 & 0.550 & - & - & 0.966 & 0.919 \\
\hline 0.5 & 50 & 0.744 & 0.747 & 0.731 & 0.666 & 0.692 & 0.481 & 0.692 & 0.481 & - & - & 0.743 & 0.644 \\
\hline 0.5 & 100 & 0.835 & 0.856 & 0.837 & 0.751 & 0.735 & 0.510 & 0.735 & 0.510 & - & - & 0.838 & 0.728 \\
\hline 0.5 & 200 & 0.923 & 0.962 & 0.924 & 0.835 & 0.660 & 0.440 & 0.660 & 0.440 & - & - & 0.912 & 0.824 \\
\hline 0.5 & 500 & 0.987 & 0.998 & 0.994 & 0.960 & 0.768 & 0.643 & 0.776 & 0.596 & - & - & 0.944 & 0.943 \\
\hline 0.5 & 1000 & 0.999 & 1.000 & 1.000 & 0.995 & 1.000 & 0.000 & 0.670 & 0.592 & - & - & 0.980 & 0.999 \\
\hline 1.0 & 50 & - & 0.951 & 0.535 & 0.739 & 0.692 & 0.481 & 0.692 & 0.481 & - & 0.807 & 0.618 & 0.655 \\
\hline 1.0 & 100 & - & 0.997 & 0.573 & 0.824 & 0.735 & 0.510 & 0.735 & 0.510 & - & 0.937 & 0.663 & 0.717 \\
\hline 1.0 & 200 & - & 1.000 & 0.645 & 0.905 & 0.660 & 0.440 & 0.660 & 0.440 & - & 0.990 & 0.723 & 0.765 \\
\hline 1.0 & 500 & - & 1.000 & 0.774 & 0.969 & 0.768 & 0.643 & 0.768 & 0.643 & - & 1.000 & 0.776 & 0.838 \\
\hline 1.0 & 1000 & - & 1.000 & 0.865 & 0.996 & 1.000 & 0.000 & 0.000 & 1.000 & - & 1.000 & 0.822 & 0.899 \\
\hline
\end{tabular}




\section{YAYA \& SHITTU}

\section{Conclusion}

Two variants of LSTAR models were proposed which realized time series data with improved symmetry over the existing LSTAR model, which is known to be asymetric. These proposed models were the AELSTAR and QLSTAR models. Monte Carlo experiment was set up, and selections of the nonlinear model was based on Teräsvirta Procedure (TP) and Escribano and Jordá Procedure (EJP). The two selection procedures selected models at frequencies lower than that of the LSTAR model, and this implied more frequencies of selection of symmetric variants of the model. The selection frequency increased as nonlinearity power in the model and sample sizes increased. This work therefore presents the AELSTAR and QLSTAR models as better alternatives to the existing LSTAR model in empirical economic and financial modeling.

\section{References}

Acemoglu, D., \& Scott, A. (1994). Asymmetries in the cyclical behaviour of UK labour markets. The Economic Journal, 104(427), 1303-1323. doi:

\section{$10.2307 / 2235450$}

Adebile, O. A. (2007). Specification, estimation and evaluation of smooth transition autoregressive models (Unpublished doctoral thesis). Department of Statistics, University of Ibadan, Ibadan, Nigeria.

Aslanidis, N., Osborn, D. R., \& Sensier, M. (2002). Smooth Transition

Regression Models in UK Stock Returns (Working Paper). Retrieved from http://fmwww.bc.edu/RePEc/res2002/Aslanidis.pdf

Baum, C. F., Caglayan, M., \& Barkoulas, J. T. (1998). Nonlinear adjustment to purchasing power parity in the post-Bretton Woods era (Working Paper Number 404). Retrieved from http://fmwww.bc.edu/ec-p/wp404.pdf

Chan, K., \& McAleer, M. (2001). Maximum likelihood estimation of STAR and STARGARCH models: A Monte Carlo analysis. Journal of Applied Econometrics, 175(5), 509-534. doi: 10.1002/jae.686

Chan, K., \& McAleer, M. (2003). On the structure, asymptotic theory and application of STAR-GARCH models (Unpublished Manuscript). 


\section{LOGISTIC SMOOTH TRANSITION}

Chan, K., \& Tong, H. (1986). On estimating thresholds in autoregressive models. Journal of Time Series Analysis, 7(3), 179-190. doi: 10.1111/j.14679892.1986.tb00501.x

Dueker, M., Sola, M., \& Spagnolo, F. (2006). Contemporaneous threshold autoregressive models: Estimation, testing and forecasting (Working Paper 2003024C). Retrieved from https://research.stlouisfed.org/wp/2003/2003-024.pdf

Escribano, A., Franses, P. H., \& van Dijk, D. (1998). Nonlinearities and Outliers: Robust Specification of STAR Models (Econometric Institute Research Report 9832/A).

Escribano, A., \& Jordá, O. (1999). Improved testing and specification of smooth transition regression models. In P. Rothman (Ed.), Nonlinear time series analysis of economic and financial data (pp. 289-319). Boston, MA: Kluwer.

Escribano, A., \& Jordá, O. (2001). Testing nonlinearity: Decision rules for selecting between logistic and exponential ST AR models. Spanish Economic Review, 3(3), 193-209. doi: 10.1007/PL00011442

Granger, C. W. J., \& Teräsvirta, T. (2006). Modelling nonlinear economic relationships. Shanghai, China: Shanghai University of Finance and Economics Press.

Liew, V. K. S., Ahmad, Z. B., \& Sie-Hoe, L. (2002). Forecasting performance of logistic smooth transition autoregressive exchange rate model: The original and reparameterised versions (MPRA Paper 511).

Lin, K-P. (2001). Computational econometrics: GAUSS programming for econometricians and financial analysts. Los Angeles, CA: ETEXT Publishing.

Lopes, H. F., \& Salazar, E. (2006). Time series mean level and stochastic volatility modelling by smooth transition autoregressions: A Bayesian approach. Advances in Econometrics, 20(2), 225-238. doi: 10.1016/S0731-9053(05)20028-2

Öcal, N. (2000). Nonlinear models for U.K. macroeconomic time series. Studies in Nonlinear Dynamics \& Econometrics, 4(3), 123-135. doi: 10.2202/1558-3708.1061

Siliverstovs, B. (2005). The Bi-parameter smooth transition autoregressive model. Economics Bulletin, 3(23), 1-11. Retrieved from http://www.accessecon.com/pubs/eb/default.aspx?topic=Abstract\&PaperID=EB$05 \mathrm{C} 50003$

Skalin, J., \& Teräsvirta, T. (1996). Another look at Swedish business cycles (Working Paper Series in Economic and Finance, Number 130). 


\section{YAYA \& SHITTU}

Skalin, J., \& Teräsvirta, T. (1998). Modelling asymmetries in unemployment rates (Working Paper Series in Economic and Finance, Number 262).

Teräsvirta, T. (1994). Specification, estimation, and evaluation of smooth transition autoregressive models. Journal of the American Statistical Association, 89(425), 208-218. doi: 10.1080/01621459.1994.10476462

Teräsvirta, T., \& Anderson, H. M. (1992). Characterizing nonlinearities in business cycles using smooth transition autoregressive models. Journal of Applied Econometrics, 7(Supplement S1), S119-S136. doi: 10.1002/jae.3950070509

Teräsvirta, T., Lin, C-F. J., \& Granger, C. W. J. (1993). Power of the neural network linearity test. Journal of Time Series Analysis, 14(2), 209-220. doi: 10.1111/j.1467-9892.1993.tb00139.x

Teräsvirta, T., van Dijk, D., \& Medeiros, M. C. (2005). Linear models, smooth transition autoregressions, and neural networks for forecasting of macroeconomic time series: A re-examination. International Journal of Forecasting, 21(4), 755-774. doi: 10.1016/j.ijforecast.2005.04.010

Tsay, R. S. (2005). Analysis of financial time series (2nd ed.). Hoboken, NJ: Wiley-Interscience.

van Dijk, D. (1999). Smooth transition models: Extensions and outlier robust inference (Doctoral thesis). Thela Thesis, Amsterdam. Retrieved from http://hdl.handle.net/1765/1856

van Dijk, D., Teräsvirta, T., \& Franses, P. H. (2002). Smooth transition autoregressive models-A survey of recent developments. Econometric Reviews, 21(1), 1-47. doi: 10.1081/ETC-120008723

Woodward, G., \& Anderson, H. M. (2009). Does beta react to market conditions? Estimates of 'bull' and 'bear' betas using a nonlinear market model with an endogenous threshold parameter. Quantitative Finance, 9(8), 913-924. doi: 10.1080/14697680802595643 